\title{
Enhanced Public Open Spaces Planning in Saudi Arabia to Meet National Transformation Program Goals
}

\author{
Abdullah Addas \\ Department of Landscape Architecture, Faculty of Architecture \& Planning, King Abdulaziz University, Jeddah, Saudi Arabia \\ Email: aaddas@kau.edu.sa
}

How to cite this paper: Addas, A. (2020). Enhanced Public Open Spaces Planning in Saudi Arabia to Meet National Transformation Program Goals. Current Urban Studies, 8, 184-204.

https://doi.org/10.4236/cus.2020.82010

Received: March 31, 2020

Accepted: April 26, 2020

Published: April 29, 2020

Copyright (c) 2020 by author(s) and Scientific Research Publishing Inc. This work is licensed under the Creative Commons Attribution International License (CC BY 4.0).

http://creativecommons.org/licenses/by/4.0/

\begin{abstract}
Public open spaces offer social, health, environmental and economic benefits to cities and their residents. As planners seek to realize these benefits and respond to human demand, different approaches have emerged; ranging from the opportunistic use of land as it becomes available, to more systematic methods. In Saudi Arabia, the current approach is predominantly opportunistic and purely quantitative, which presents a challenge to the Ministry of $\mathrm{Mu}$ nicipal and Rural Affairs (MoMRA) as it seeks to meet the National Transformation Program goal of increasing public open space per capita from 3.4 $\mathrm{m}^{2}$ to $3.9 \mathrm{~m}^{2}$. This study set out to identify ways of improving the planning and design of public open spaces in Saudi Arabia, by reviewing 20 open spaces (five each in Taif, Hail, Tabuk, and Abha) and interviewing municipality officers. The findings of this review indicate that MoMRA and the municipalities in Saudi cities need to adopt a system of collaboration to support the implementation of public open spaces, by: 1) introducing qualitative design guidelines in order to reduce dependence on the square meter measure and encourage smart design and location of open spaces within the urban fabric; 2) creating incentives for further connectivity of public spaces at the city-wide level; and, 3) improving the functions of open spaces to match community needs through a more participative approach, including citizen engagement. Responding to these key challenges will require the capacity to be built in both MoMRA and the municipalities, to unblock the expertise that local planners and designers have in the urban transformation of Saudi cities and to ensure that decision-making processes are effective. These changes will benefit from a public open space typology, and a system and network to be implemented country-wide.
\end{abstract}

\section{Keywords}

Planning, Public Open Spaces, National Transformation Program, 
Municipalities, Saudi Arabia

\section{Introduction}

A range of studies have identified the contribution that public open spaces can make in terms of social benefits (Francis, 1995; Bishop \& Curtis, 2001; Addas \& Rishbeth, 2018), health benefits (Armstrong, 1993; Beveridge \& Rocheleau, 1995; Bundred et al., 2001; Addas \& Rishbeth, 2018), environmental benefits (Chandler, 1978; Noble et al., 2000), and economic benefits (Danzer, 1987; Rugg, 2000; Somper, 2001). Public spaces are essential for city dwellers, to support their social interactions and recreational activities. The landscape offers physical and visual coherence as well as creating an identity to the spaces, helping users and residents develop a sense of belonging through the landscape design of public open spaces, including green spaces, parks, waterfronts and riverbanks.

Research suggests that several factors may affect the use of public open spaces, including attractiveness, proximity, facilities, accessibility, safety, condition and distribution (Akpinar, 2016; McCormack et al., 2010). Furthermore, the diversity of public open space features that encourage users to engage in different kinds of active and sedentary activities is important for all age groups (van Hecke et al., 2016). In addition, evidence shows that physical activity is associated with environmental variables and neighborhood contexts (Brownson et al., 2000; Ross, 2000).

Open space distribution and planning can either encourage or discourage the use of spaces, with equity of access linked to methods and policies of distribution equality. Evidence from social science research shows that three factors should guide the process of design and management of public spaces: $i)$ the essential needs of people, ii) their spatial rights, and iii) the meaning they seek (Carr et al., 1992). However, as planners look to respond to human demand for recreation, amenities and environmental quality, different approaches have emerged, ranging from the opportunistic use of land that becomes available, to systematic methods including a park system model and a quantitative space standards model (Maruani \& Amit-Cohen, 2007).

The opportunistic approach, with the absence of a systematic planning process, has created an old pattern of public open spaces, with well-known examples around the world, of land donated by monarchs or wealthy families, such as in London and Paris. In addition, public open spaces result from upgrading slums (Schenker, 1995), environmental enhancement (Runte, 1987), and conversion of waste dumps and scrap yards (Maruani \& Amit-Cohen, 2007).

Another variant of the opportunistic pattern is "space left over after planning" (SLOAP) (Maruani \& Amit-Cohen, 2007). This is the space that remains after allocating land use or road engineering projects. However, these leftover spaces are usually in random shapes, hard to access, and are usually not intended for use by the public. Central Park in New York, Cairo Al-Azhar Park, and the Bou- 
levards of Paris, are famous examples of the opportunistic model of public open spaces, yet the opportunistic pattern lacks a systematic outcome based on any principle. In addition, this model cannot fulfill population needs or protect natural resources.

It can be argued from the examples of the opportunistic pattern, that it is successful and has provided cities with adequate parks. However, these parks were integrated with city green open spaces networks after implementation to ensure that they serve the population. This paper examines spaces in Saudi Arabia that have resulted from the opportunistic pattern, because the provision of public open spaces in Saudi cities relies on the spaces left over after planning (SLOAP).

This predominantly opportunistic approach does not ensure a sufficient response to human needs (Maruani \& Amit-Cohen, 2007). The result is that, while public open spaces in the Saudi Kingdom are heavily used, some spaces are in poorly chosen "leftover" locations (Figure 1).

One of the root causes of the absence of a systematic approach is a lack of understanding of the fields of planning and landscape architecture, meaning that public open spaces in the country are designed and managed by non-specialists. In addition, the planning of these spaces is not implemented in the early stages of a city's development master plan (Addas, 2018), and responsibility for open spaces has historically been confused and fragmented in the absence of a robust institutional framework (Mandeli, 2010). Recently, some measures have been taken to encourage public participation, especially through the extensive use of social media. Citizen engagement has been introduced with a promising level of success. However, such tools are still not used for design purposes, to understand (Addas, 2017) people's needs and preferences; rather, these tools are used by ministries and municipalities mainly as a means of ensuring political support.

Saudi Arabia is now at a point where the use of public open spaces for leisure activities needs to be addressed systematically following the rapid expansion of urban areas. The ability to do so exists, with the growth of the landscape profession and involvement of Western landscape architecture (Addas, 2015; Addas \& Rishbeth, 2018). Particular issues that need to be addressed include providing ways of helping to reduce the segregation between the many different nationalities who live together in parts of Saudi Arabia, but who are often isolated within gated communities (Mandeli, 2011). In addition, planning must reflect the cultural heritage of Saudi Arabian cities and be consistent with Islamic teaching, since Islam is the predominant religion in this region. Planning of public open spaces must also reflect the major changes that have taken place in Saudi Arabia over the past three years, as the country aims to become one of the leading countries in the Middle East and worldwide. These changes reflect the strategic objectives of Vision 2030, such as improving livability and improving the urban landscape in Saudi cities.

The National Transformation Program in Saudi Arabia (NTP) recognizes the need to manage open spaces more effectively and aims to increase public space 
per capita from $3.4 \mathrm{~m}^{2}$ to $3.9 \mathrm{~m}^{2}$ by 2030 . This increase in coverage of open spaces in the country will be a significant challenge for the Ministry of Municipal and Rural Affairs (MoMRA), because of the current planning and management practices associated with public open spaces (Addas \& Alserayhi, 2020; Mandeli, 2010). While it has been challenging to increase public open spaces per capita since the establishment of the NTP and Vision 2030, MoMRA, and the municipalities in large Saudi cities, are taking serious steps toward this goal. MoMRA efforts include reviewing the legislation and policies of public open spaces provision. Likewise, Riyadh, for example, announced the Green Riyadh project, which aims to increase the public open spaces per capita in the city and enhance livability.

The aim of this study was to identify ways of improving the planning and design of public open spaces in Saudi Arabia. The study was based on a combination of quantitative and qualitative research design and included survey-based research to address the targeted objectives. The study focused on four cities in Saudi Arabia (Taif, Hail, Tabuk, and Abha), and reviewed the planning and distribution of five public open spaces in each city.

\section{Methodology}

To assess the urban setting, this study examined the physical environment of the selected public open spaces, as considered in urban design and planning literature (Carp \& Carp, 1984; Kallus 2001; Kahana et al., 2003). This research investigated only the planning and design of the selected sites and attempted to identify ways of enhancing the planning of public open spaces to support the NTP goal of increasing public open spaces per capita. The research did not explore the pattern of use of these spaces or whether the spaces were meeting people's needs. The research aimed to identify only the weaknesses in the planning and design of the public open spaces in the kingdom, as implemented by the municipalities.

In order to gain a better understanding of the landscape design of public open spaces in Saudi Arabia, a multiple case studies method was used (De Vaus, 2001). This method helped the researcher develop the required understanding of the approach of municipalities in different cities within the kingdom, and the ways of providing public open spaces. Four cities were selected; one each in the north, south, east, and west of the kingdom (Figure 2) to ensure regional representation. These cities were selected by running a random table of all cities in Saudi Arabia which have historical and particular regulations for the design of public open spaces, excluding the largest cities of Makkah, Riyadh, Jeddah, and Dammam because these cities considered the mega city and the other cites or regions are promising regions. Within each city, a survey by car was conducted to identify the public open spaces that would form part of the study. The car survey technique was chosen to investigate the various types of open spaces in each city where unplanned places had been selected by users, such as rounda- 
bouts, pavements, and spaces by the sides of roads, as these demonstrate regular patterns of use for leisure and recreation activities. Five spaces in each city were selected according to their geographical location, as well as their scale.

The sites were selected to enable the planning practices applicable to public open spaces to be examined in order to meet the study aim of identifying ways of improving the planning and design of these spaces. The author sought to select a variety of sites within the urban context of each city, thus bringing to light different planning practices. The sites included developed and undeveloped sites, used and unused sites, and sites of different scale. Each city has examples of good quality public open spaces, such as Arruddaf Park in Taif; however, these spaces were considered to be city-scale spaces that serve visitors from outside the city. This study focused on the spaces that are near to, or within, residential areas, and so the city-scale spaces were excluded from the analysis. In addition, these city-scale sites are managed by a higher authority than the municipalities, such as by MoMRA; this study considered sites within the jurisdiction of the municipalities.

The researcher conducted four to five days' observation in each city, including normal weekdays and weekends, to ensure that a full understanding could be gained as to whether the selected sites were used by residents. The observations took place between August 2018 and May 2019.

It is important to note that the social circumstances of the selected cities were similar in terms of demographics, culture, ethnicity, and language. Moreover, the research focused on the spatial arrangement differences between the selected open spaces in each city, regardless of demographics. Three factors were assessed in the case study sites: i) design and planning, ii) location, and iii) space quality.

Between March and May 2019, nine interviews were held with the municipal officers responsible for open space design and management, from the planning department, design and studies department, and creativity department. All interviewees asked to remain anonymous. The interviews were conducted in Arabic, and the questions addressed the issue of provision of public open spaces in each city. The following are the main questions used in the interviews:

- How would you evaluate the current practice of public open spaces in your division?

- Do you have guidelines and policies for planning, designing, managing, and operation of public open spaces?

- Which, in your opinion, is the priority: creating new spaces, or managing and maintaining existing spaces?

- What is the site selection criteria for creating new public open spaces, and what are the requirements regarding activities and facilities?

- What is the level of engagement of the users and stakeholders that your authority conducts before creating new spaces?

- What are the most significant problems facing the provision of public open spaces? 
- What is the measurement of quality and value in public open spaces planning?

\section{Case Study Sites Overview and Analysis}

The review of the selected sites was carried out in regard to the spatial arrangements of each site, based on the feedback received from the interviews. This review included amenities, accessibility, safety, maintenance, usage diversity, and aesthetic quality of the space. These factors are critical, because their combination determines the success and quality of public open spaces and their ability to satisfy users, as has been pointed out in the specialized international literature (Sirgy \& Cornwell, 2002; Francis et al., 2012; Gürer et al., 2017). Table 1 below explains the spatial arrangement differences considered for each of the selected sites in relation to design factors. Further, for each selected site, a similar table of spatial arrangement analysis will be provided to identify which of the approaches and spatial arrangements previously mentioned are applicable to the study sites.

The review of the selected sites is presented in three stages for each city. The first stage is a description of the city, giving general information about the city

Table 1. Selected sites' design approaches and spatial arrangement analysis.

\begin{tabular}{|c|c|}
\hline Factors & Spatial arrangement \\
\hline \multirow[t]{4}{*}{ Accessibility } & Pedestrian continuity \\
\hline & Parking \\
\hline & Special needs-friendly \\
\hline & Barrier-free \\
\hline \multirow[t]{3}{*}{ Activities and programming } & Consider different ages and genders \\
\hline & Various activities \\
\hline & Social events \\
\hline \multirow[t]{3}{*}{ Aesthetic quality } & Site image \\
\hline & Various usable site furniture \\
\hline & Public art \\
\hline Amenity & Availability of vendors \\
\hline \multirow[t]{4}{*}{ Maintenance } & Softscape \\
\hline & Hardscape \\
\hline & Lighting \\
\hline & Site furniture \\
\hline \multirow[t]{3}{*}{ Safety } & Pedestrian privileged arrangement \\
\hline & Lighting spots (night-use friendly) \\
\hline & Not isolated from surroundings \\
\hline User diversity & $\begin{array}{l}\text { Brings together users from different social and } \\
\text { cultural backgrounds }\end{array}$ \\
\hline
\end{tabular}


Table 2. Case study cities' general information.

\begin{tabular}{|c|c|c|c|}
\hline City & Province & Population & Nationality Saudi-Migrants \\
\hline Taif & Makkah & 579,970 & $442,984-136,986$ \\
\hline Hail & Hail & 310,897 & $240,916-69,981$ \\
\hline Tabuk & Tabuk & 512,629 & $432,429-80,200$ \\
\hline Abha & Aseer & 231,157 & $177,905-58,252$ \\
\hline
\end{tabular}

Source: Central Department of Statistic and Information, Ministry of Economy and Planning.

location and its main attractions. The second stage provides details of the selected sites, with general information and data, including site layout, area, year built, location, user diversity, usage diversity, and site amenities. In the third stage, a summary of the spatial arrangements of each site is provided according to the design approaches presented in Table 1. A comparative analysis of these site reviews is then provided. Table 2 indicates province for each city and the current population, and numbers of local and migrant residents.

Each one of the study sites will be explained using composite table for each city. This table will include layout for each site which identifies the surrounding context. In addition, general data such as area, built in year, user type and using time. This table will include the amenities in each site with supporting photos. It will highlight the location, which means whether is on roadway, roundabout or cloverleaf.

\subsection{Taif}

Taif is a city in the Makkah Province of southwest Saudi Arabia, at an elevation of $1879 \mathrm{~m}$ on the slopes of the Sarawat Mountains. It is the fifth-largest city in the country and is one of the country's principal agricultural cities. Taif Municipality has two technical departments responsible for the provision of the city's public open spaces: the Gardens and Beautification Department, and the Afforestation Department.

Five sites were selected in Taif, according to site design, planning, and location and space quality. These sites were designed by the municipality technical departments (Figure 1), and are described in Figure 1.

In Taif, accessibility is a common issue in all of the sites, and this affects users' safety. The sidewalks and pavements are not well-maintained in the selected sites. In addition, only one of the selected sites provides vendors (study site 3 ), and all sites lack programming and events.

\subsection{Hail}

Hail is a city in Hail Province, in the north of Saudi Arabia. The city is bordered to the west by Aja and the Salma Mountains. The cultural, historical, and ancient monuments are the most important pillars of tourism activity in the city and contribute greatly to supporting the Hail economy. 


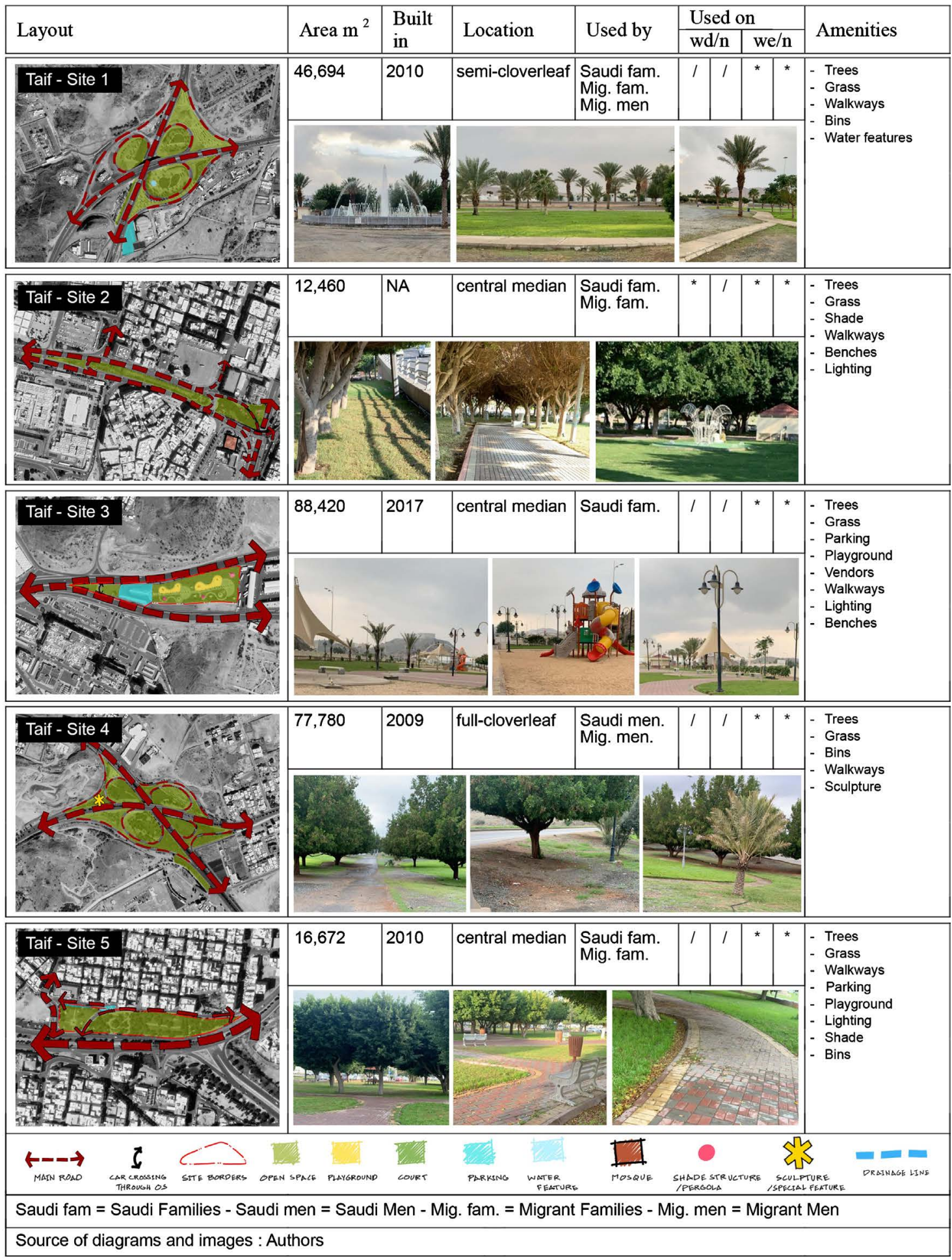

Figure 1. Taif study site details.

Hail Municipality has a technical department responsible for the provision of public open spaces in the city, the Gardens and Beautification Department. The sites selected in Hail were designed by the municipality technical departments (Figure 2) and are described in Figure 2. 


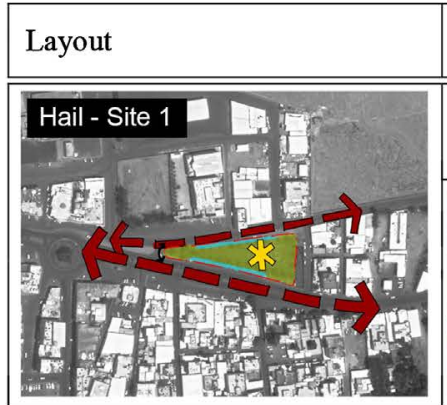

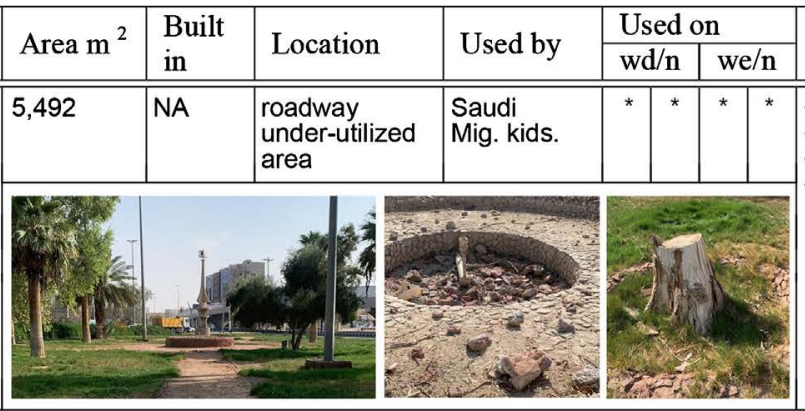
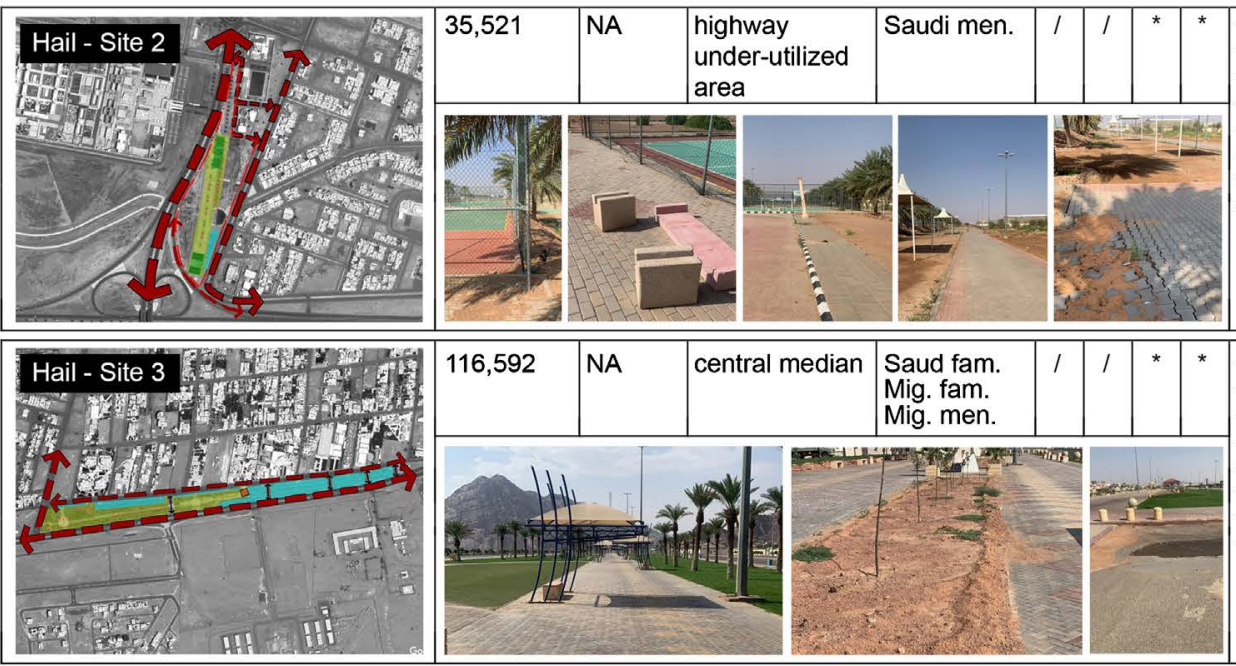

- Basketball
- Bins
- Football pitch
- Lighting
- Parking
- Planting
- Shade
- Volleyball
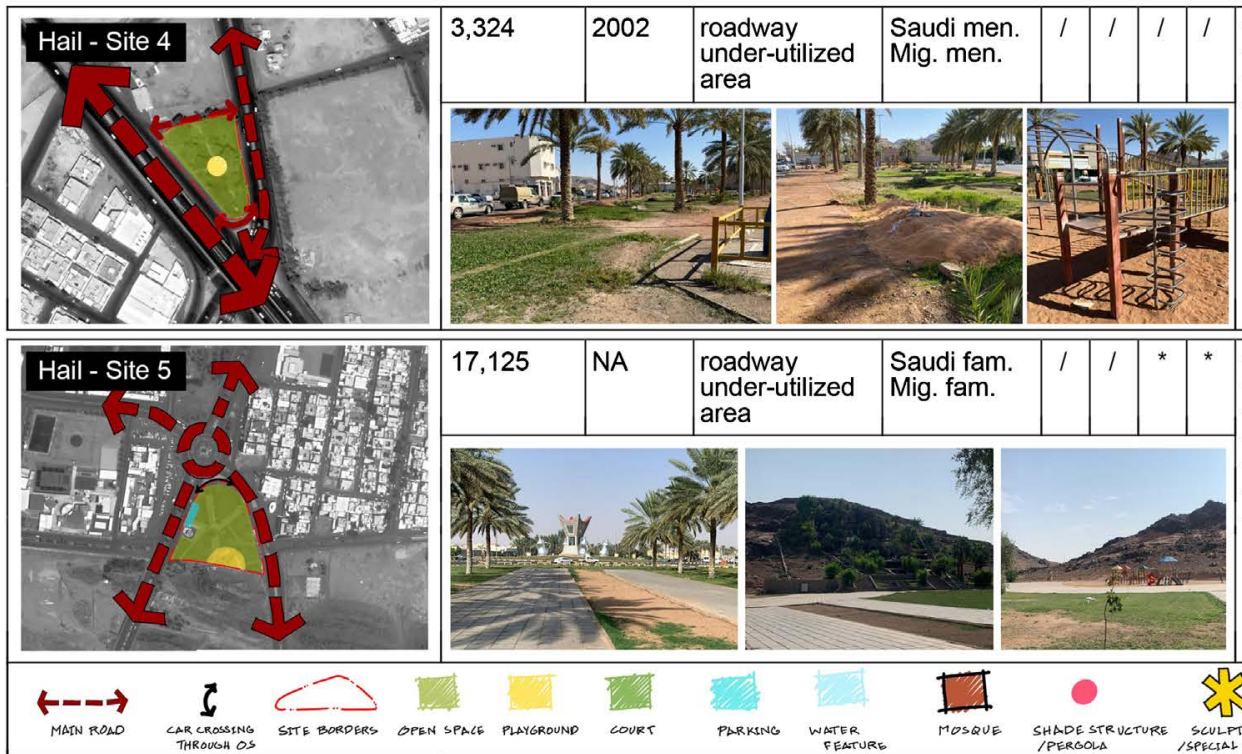

- Lighting

- Mosque

Parking

Planting

Shade

Walkways

Saudi fam = Saudi Families - Saudi men = Saudi Men - Mig. fam. = Migrant Families - Mig. men = Migrant Men - Saudi kids

$=$ Saudi children - Mig. kids. $=$ Migrant children

Source of diagrams and images : Authors

Figure 2. Hail study site details.

The key aspects of the sites in Hail are similar to Taif in regard to accessibility, which affects users' safety because all of the selected sites are located in roadways (under-utilized area or in the central median). Further, the level of maintenance on the selected sites is lower compared to Taif and the other study cities. 


\subsection{Tabuk}

Tabuk is a city in Tabuk Province and is the largest city in the north of Saudi Arabia. The city is considered as the gateway from the north of the country and is a very important agricultural city.

Tabuk Municipality has a technical department responsible for the provision of public open spaces in the city; the Services Department. The five sites selected, which were designed by the municipality (Figure 3), are described in Figure 3.

The key aspects of the sites in Tabuk are similar to Taif and Hail in regard to accessibility, which affects users' safety, although all of the selected sites have parking areas. In addition, the sites in Tabuk are not isolated from the surrounding area, which enhances the sense of security compared with Taif and Hail. The lighting in the selected sites is well-maintained, which encourages the use of these sites at night.

\subsection{Abha}

Abha is a city in Aseer Province in the south of Saudi Arabia. It is an important tourist city in Saudi Arabia because of its climate, which is related to its high altitude. The city is surrounded by mountains on all sides except the north and northeast.

Abha has no municipality but follows the Aseer Municipality and the technical department responsible for the provision of public open spaces in the city of Aseer; the Garden Department. Five sites were selected. These were designed by the municipality technical department (Figure 4) and are detailed in Figure 4.

The key aspects of the sites in Abha are similar to the sites of the other cities in terms of planning and spatial arrangement. The level of accessibility is very limited because of the lack of continuity and the absence of consideration for special needs users. In addition, there is a clear lack of programming and fun activities. Further, the sites have low maintenance of lighting features, which is why most of the sites are not used at night.

\subsection{Comparative Analysis of the Selected Sites}

It is important to note that research in the Saudi Arabian urban context has identified the importance of public open spaces and examined the demand on these spaces and how residents interact with them (Mandeli, 2019; Abubakar \& Aina, 2018; Atef Elhamy Kamel, 2013; Al-Hathloul \& Mughal, 2004; Al-But'hie \& Eben Saleh, 2002; Saleh, 1998). While these aspects were not the main focus of this study, it has highlighted the significance of how open spaces are used within the urban setting. Although there are regional differences in the selected case studies, it can be seen that similar challenges exist in designing and operating the public spaces that are the focus of public investment and community use, with serious problems of access and quality. The relationship found in terms of design and planning, followed by maintenance and security related to actual use, amenities, aesthetics and urban functions, must be highlighted as a key output of this research. 
From the review of the design factors considered for the selected sites, we can identify the spatial arrangements of each site. Table 3 below presents the summary of each of the arrangements, and to what extent it is applicable to each of the sites. Pedestrian continuity is a common issue in all the selected sites, and

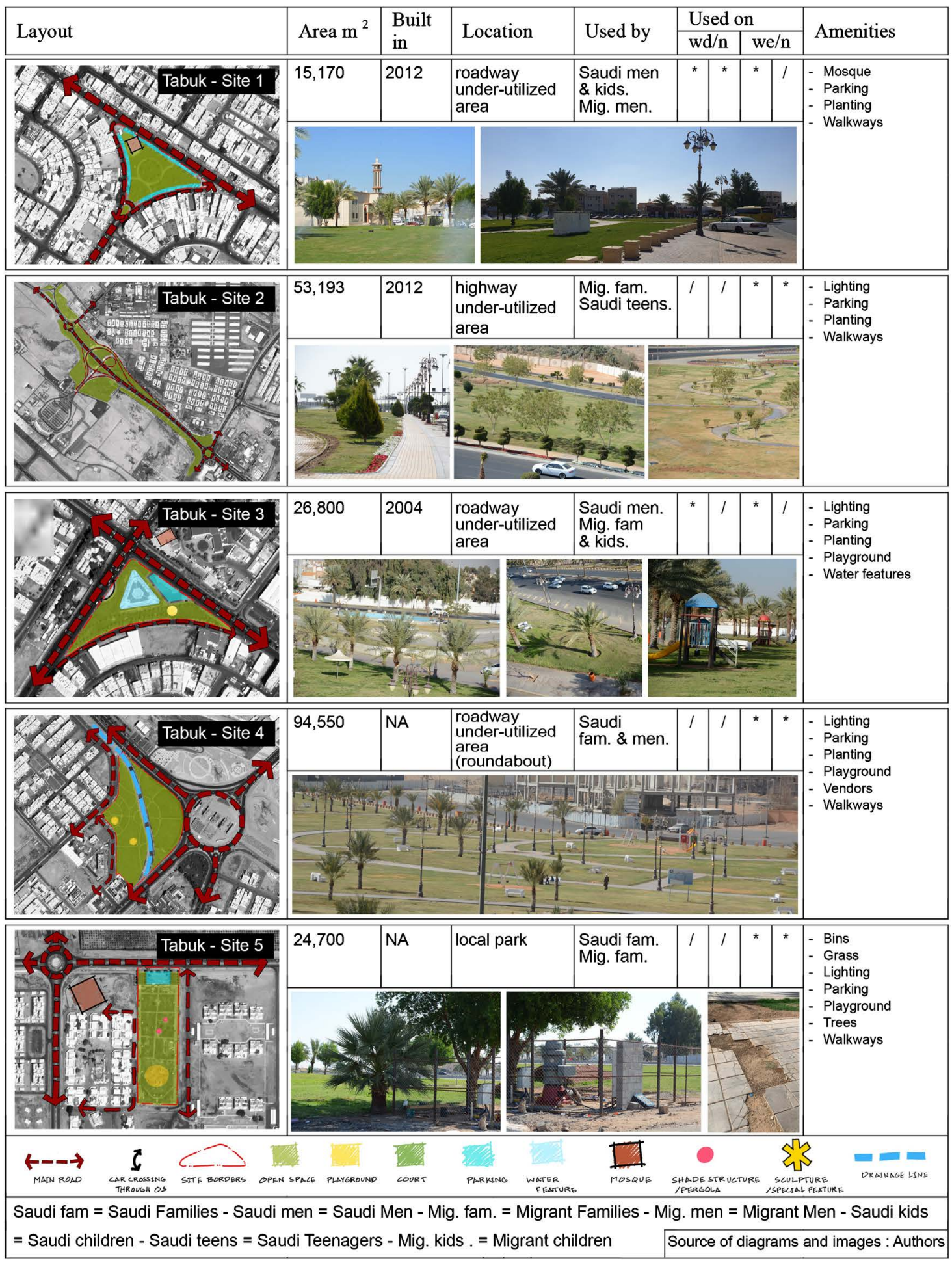

Figure 3. Tabuk study site details. 


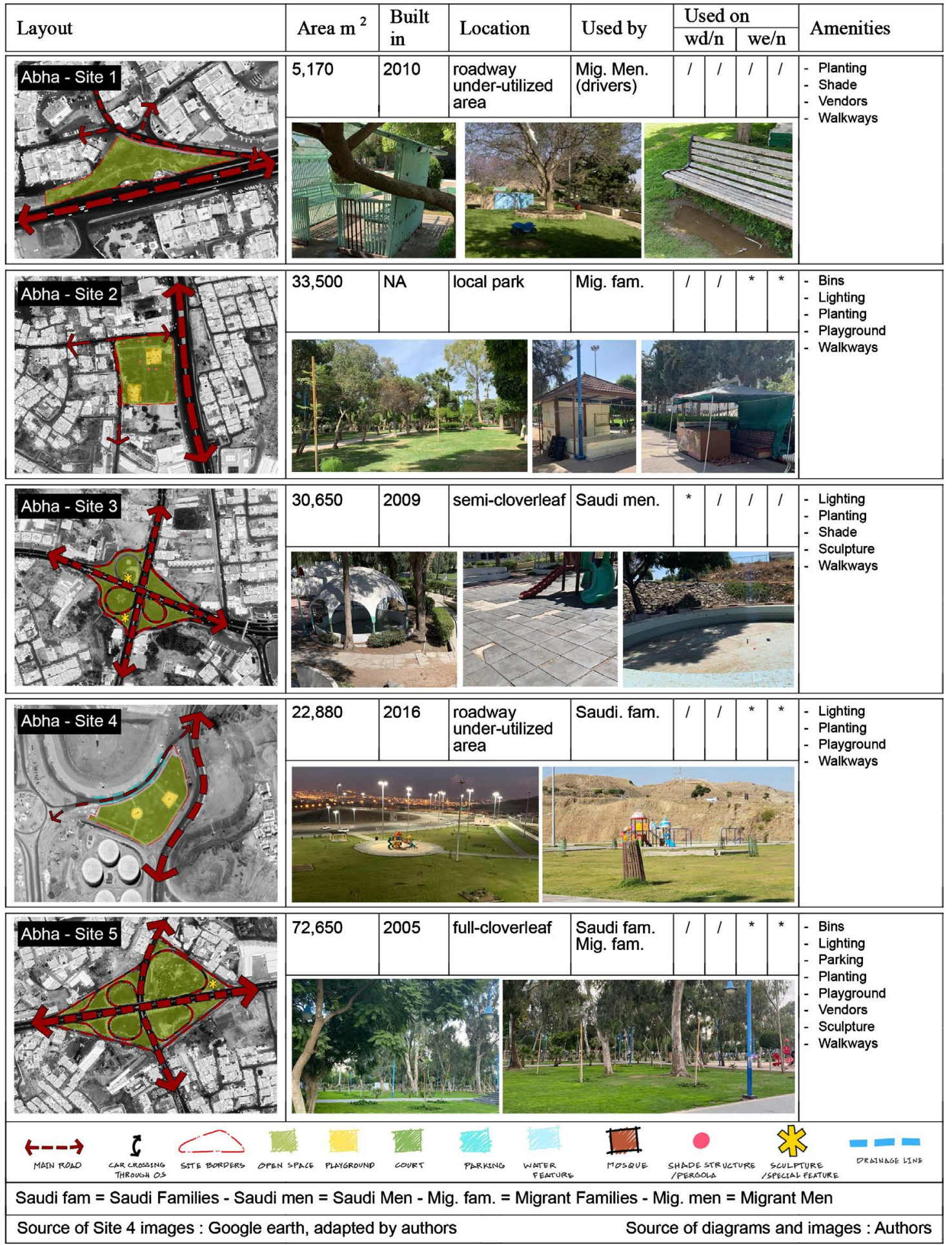

Figure 4. Abha study site details.

this is due to the planning approach to public open spaces and the lack of public open spaces networks in the cities. In addition, accessibility for people with special needs, and parents with pushchairs, is a major issue that was identified in $90 \%$ of the selected sites. This issue prevents people from accessing the sites eas- 
ily, and affects their safety, particularly because of the random street crossing points to reach the sites (only $5 \%$ of the selected sites provide safety for pedestrians). From Table 3, we can see that $60 \%$ of the sites provide activities for users. However, it is important to note that the activities are mainly children's

Table 3. Comparison of spatial arrangements between sites.

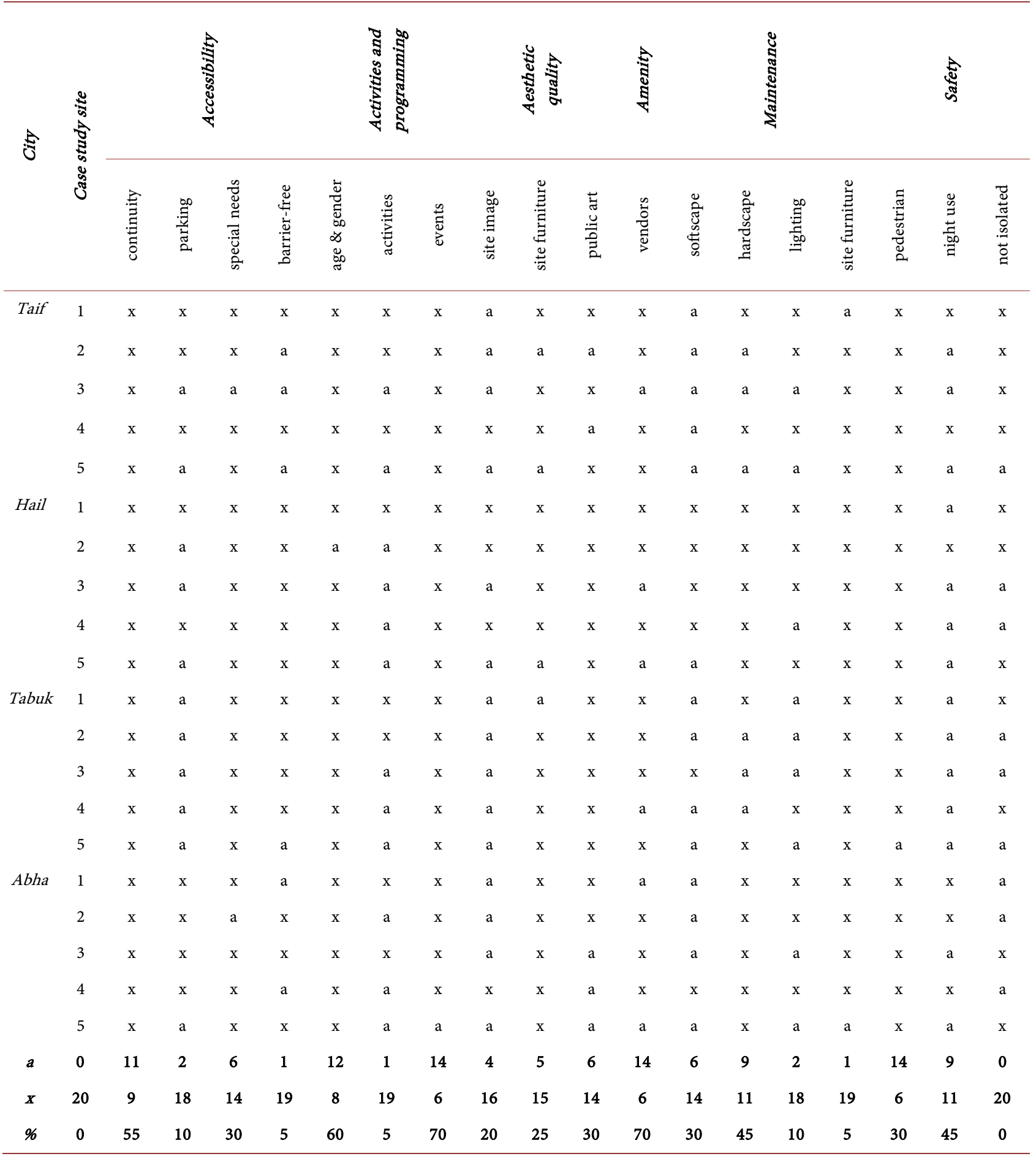

$\mathrm{a}=$ present, $\mathrm{x}=$ absent. 
playgrounds for certain age groups only; activities for other users from different age groups are largely neglected. It was found that maintenance of the hardscape and other site furniture is very poor, and does not appear to have been considered in most of the selected sites; however, lighting is well-maintained in $45 \%$ of the selected sites to promote use after $5 \mathrm{pm}$, which is the norm in Saudi Arabia because of the climate and various social aspects.

Table 3 reflects several design and planning failures. Among them, the fact that people need to walk long distances to access available public spaces is a particular problem, as is the fact that these spaces are not connected among themselves. There is also a lack of a clear hierarchy of such areas serving community use. This complicates maintenance and explains why most of the spaces researched are in a state of disrepair. Ferre et al. (2006), Krenichyn (2006), and Lloyd et al. (2008) commented that having local parks within walking distance of people's homes is positively associated with the usage level of local parks. In contrast, the necessity to drive to reach a park often deters use (Henderson et al., 2001; Griffin et al., 2008).

\section{Findings and Discussion}

The findings and discussion can be divided into two main parts to address the issues: first, public open spaces design and planning; and second, maintenance and operation. From the analysis of the selected public open spaces in the four cities, it is evident that there is a lack of understanding of the techniques and methods of design and planning, and maintenance and operation, to provide cities with accessible, well-connected and user-friendly public open spaces.

\subsection{Design and Planning}

From the review of the four selected cities, there appears to be no common view of what should be considered as a usable public open space. More importantly, the concept of public open space as a proper use of land is given far lower priority during the planning and implementation process than other land uses. Open spaces are only considered within the $33 \%$ reserve for fiscal land, which is generally in poor locations and not really inserted within the urban fabric. Public open spaces are typically designed on cloverleaf interchanges, roadways and central medians, due to lack of consideration of issues such as the definition of public spaces, the typology of open spaces, and the benefits of these spaces to cities and their residents. MoMRA has no clear definition of public open spaces, applying only rigid quantitative indicators without consideration of the quality of these spaces, including their functionality, and how these spaces should be managed to ensure effective maintenance and operation. Further, the characteristics of public open spaces are not specified in the guidelines of MoMRA. This lack of understanding leads to the use of underutilized areas of roadway, which are mostly leftover spaces from road design projects. There is a range of international practices of using underutilized areas of roadway, which includes types of criteria 
and standards that must be considered when building such spaces. Practices considered for the use of these interim spaces are to convert them into plazas.

From the review of the sites in the four cities, it was discovered that transforming interchange cloverleaf spaces into usable public open spaces is a very common practice in the Kingdom of Saudi Arabia. The study confirmed that injuries and fatalities are generally elevated in the immediate vicinity of these interchanges. These interchange leftover-designed public open spaces in the studied cities are considered very dangerous locations for users. This is also due to the lack of public open space typology which needs to be created by MoMRA according to each city's geographic context and nature. The research suggests that the definition of open space typologies will assist municipalities to do much better than randomly create public open spaces in unsuitable places for people to use. Typologies will also establish the relationship between the function of the spaces, their location within an urban area, and their integration into an open space network at the city level.

Tabuk Study Site 5, and Abha Study Site 2 were located in residential neighborhoods. From the analysis of the location and planning of these two sites, we can see that the sites were randomly selected within the neighborhood without consideration to the catchment areas of the spaces, or to the spatial and demographic distribution that ensures accessibility by the majority of residents (Wen et al., 2013). Focus is only given to providing residential land use. Gardens and other public services are given less attention during the planning of neighborhood projects because MoMRA guidelines do not identify the best locations for public open spaces in such projects. Ministry guidelines simply provide details regarding size and activities.

Findings from the present research indicate that the planning of public open spaces in the selected cities neglects this factor. In addition, the catchment area for public open spaces within neighborhoods is very small, and people cannot easily walk to parks and gardens. The overall result of the focus on residential land is an expansion in population numbers without the development of the public open spaces that provide facilities for the population; a finding that echoes the views of Maruani and Amit-Cohen (2007).

From observation and analysis of the selected cities, it is apparent that there are no public open spaces networks that enhance accessibility, and this leads to spatial inequality and safety issues for residents. In addition, according to the interviews with the municipality officers, the planning process of public open spaces is missing from the city master planning stage. However, these ancillary spaces are used heavily by users, who need space for recreation, even if the location of the spaces might not be safe. This observation echoes the findings of Turner (1992), and also previous research conducted by (Addas and Alserayhi, 2020).

By examining the design of the selected sites, we found that there is a similar design approach in almost all cities, reflecting a lack of effective community 
consultation. Furthermore, creativity of design does not exist. Instead, a "copy and paste" design approach by the consultants in charge of developing these spaces, prevails, wasting local expertise and environmental knowledge, and disregarding culture. Analysis of the selected sites also showed that the art of the landscape architecture profession is somewhat neglected. In addition, there is a lack of consideration of planting design, form and geometry, landscape elements, facilities, and designed activities. According to the interviews with the municipal officers, this lack of design consideration is due to the fact that all municipal gardens are designed in the municipality, and, in many cases, those who create the designs have limited knowledge and skills in planning and landscape design, and even less in community participation and citizen engagement.

MoMRA must now take serious steps if it is to meet the NTP goal to increase public open spaces per capita, by creating well-planned public open spaces across Saudi cities. There is a need to establish a country-wide public open space typology that can be modified according to each city's population needs, geography, natural environment, and urban context. In addition, public open spaces must be planned according to a hierarchy of space, to ensure variation between the provided spaces with regard to scale and activities.

The open space typology must ensure that what Carr et al. (1992) described as the essential needs of people, their spatial rights and the meaning they seek, are fully addressed in the planning process. The opportunistic transformation of leftover spaces from roadway projects is likely to continue to be a feature of open spaces in cities, but the planning of these spaces must take account of user safety and accessibility, and allow evolution into better long-term solutions. However, the most important step is to move away from a simple opportunistic approach, and for MoMRA to set the framework which encourages systematic methods such as a park system model or a quantitative space standards model (Maruani \& Amit-Cohen, 2007). To achieve these ends, it will be necessary to build and develop municipal staff capabilities in the planning field, and also in the technical departments responsible for providing the cities with parks and gardens.

This research contributes to public open spaces planning literature and knowledge by exploring the planning, provision, and landscape architecture practices associated with developing urban public open spaces for different benefits, drawing on Western experience. Taking into consideration and implementing best practice in respect of public open spaces provision, will align Saudi cities with international planning standards and help to address shortcomings in current planning practices.

\subsection{Maintenance and Operation}

This section highlights the issue of maintenance of the studied sites and how this can also affect user behavior. Ozguner \& Kendle (2006) argue that user attitudes are influenced by the maintenance and management of public open spaces. This finding is relevant to the context of the study sites, because, from observation in 
sites with a lack of maintenance, there was evidence of neglect and anti-social behavior, including broken tiles, non-functioning water features, planting that required trimming, grass that needed to be mown, broken children's play equipment, and broken lighting. These factors negatively influence the usage pattern of these spaces, and indicate that landscape design and maintenance has generally failed in enriching the environment of these spaces (Addas, 2015).

Municipalities need to consider that their responsibility does not end simply in providing the spaces and that operation and maintenance are important to ensure that the parks and gardens function well. Once the quality of a site becomes degraded, it can deter people from using the space. In addition, the involvement of private and voluntary sectors, as well as participation of the public, can play an important role in the maintenance and management of public open spaces (Bradley, 2015; Dempsey \& Burton, 2012).

\section{Conclusion and Recommendation}

The government of Saudi Arabia is aiming to enhance the quality of urban life in Saudi cities, and there is a range of programs and initiatives to help the government achieve its goal. In addition, there are many KPIs that governmental organizations must achieve in order to meet the country's 2030 vision. MoMRA aims to achieve the NTP key performance indicator (KPI) to increase public open spaces per capita from $3.45 \mathrm{~m}^{2}$ to $3.9 \mathrm{~m}^{2}$ by 2020; however, MoMRA needs to be aware that the KPI will not be achieved in reality if all that is provided are poorly planned public spaces in random areas. The quality dimension of open spaces needs to be present and measured to be achieved. That said, MoMRA and the municipalities in large Saudi cities are making progress. MoMRA's efforts include reviewing legislation and policies, and cities such as Riyadh have announced projects which aim to increase public open spaces per capita and enhance livability.

MoMRA has a well-designed set of guidelines; however, the Ministry needs to go further and establish a clear definition of public open spaces to support municipalities in understanding and realizing the benefits, including the best location and how to plan the spaces. Furthermore, public open spaces are a necessity in the country, and each city municipality should move away from an opportunistic approach and instead introduce systematic methods of planning public open spaces. These methods should be based on a full appreciation of the needs of the citizens and enable the establishment of public open spaces according to context, and also the urban and rural fabrics of the city.

There is also a need for focus on developing appropriate design capabilities in MoMRA and the municipalities, to ensure they are working according to the knowledge and skills required for the technical department in relation to the provision of public open spaces. These skills should include an understanding of methods in planning public open spaces from other cities worldwide, to ensure that municipalities apply the most appropriate systematic methods in their own 
cities. Furthermore, community consultation and citizen engagement are also essential skills in designing and maintaining these spaces.

Future studies can test and calculate the area of well-planned public open spaces in particular cities in the country using geographic information systems (GIS), and compare the results with the KPI for public open spaces per capita. A city-wide vision of open space will help create a better connected and accessible open space network, overcoming the piecemeal planning approach that explains the current fragmentation of open spaces in Saudi cities. This GIS model can thus be used to discuss the planning process, and whether public open spaces deliver to citizens what they require.

This study has the potential to make a significant contribution to the academic research on planning practice for public open spaces in the Saudi Arabian context, and to a transnational understanding of the effective provision of these spaces. For both of these areas, the focus on Saudi Arabian open spaces is a rare perspective, which helps address a Western, and North European bias in the academic literature. The implications for practice are also important. This research highlights the need to improve open space planning and provision in order to address social and behavioral requirements effectively.

\section{Conflicts of Interest}

The author declares no conflicts of interest regarding the publication of this paper.

\section{References}

Abubakar, I. R., \& Aina, Y. A. (2018). Achieving Sustainable Cities in Saudi Arabia: Juggling the Competing Urbanization Challenges. In E-Planning and Collaboration (pp. 234-255). Hershey, PA: IGI Global. https://doi.org/10.4018/978-1-5225-5646-6.ch011

Addas, A. (2015). Motivation and Attachment in the Use of Public Open Spaces in Jeddah, Saudi Arabia. Unpublished Ph.D. Dissertation, Sheffield: Landscape Department, The University of Sheffield.

Addas, A. (2017). The Creation of Outdoor Spaces and Public Engagement, Jeddah, Saudi Arabia. In ECLAS Conference 2017/Proceedings Creation/Reaction (pp. 45-55). London: University of Greenwich.

Addas, A. (2018). Landscape Architecture and the Saudi Arabia Quality of Life Program. Emirates Journal for Engineering Research, 24, 21-29.

Addas, A., \& Alserayhi, G. (2020). Quantitative Evaluation of Public Open Space per Inhabitant in the Kingdom of Saudi Arabia: A Case Study of the City of Jeddah. Sage Open. https://doi.org/10.31124/advance.11420976.v1

Addas, A., \& Rishbeth, C. (2018). The Transnational Gulf City: Saudi and Migrant Values of Public Open Spaces in Jeddah. Landscape Research, 43, 939-951. https://doi.org/10.1080/01426397.2018.1427709

Akpinar, A. (2016). How Is Quality of Urban Green Spaces Associated with Physical Activity and Health? Urban Forestry \& Urban Greening, 16, 76-83.

https://doi.org/10.1016/j.ufug.2016.01.011 
Al-But'hie, I. M., \& Eben Saleh, M. A. (2002). Urban and Industrial Development Planning as an Approach for Saudi Arabia: The Case Study of Jubail and Yanbu. Habitat International, 26, 1-20. https://doi.org/10.1016/S0197-3975(01)00026-1

Al-Hathloul, S., \& Mughal, M. A. (2004). Urban Growth Management-The Saudi Experience. Habitat International, 28, 609-623. https://doi.org/10.1016/j.habitatint.2003.10.009

Armstrong, N. (1993). Promoting Physical Activity in Schools. Health Visitor, 66, 362-364.

Atef Elhamy Kamel, M. (2013). Encouraging Walk Ability in GCC Cities: Smart Urban Solutions. Smart and Sustainable Built Environment, 2, 288-310. https://doi.org/10.1108/SASBE-03-2013-0015

Beveridge, C. E., \& Rocheleau, P. (1995). Frederick Law Olmsted: Designing the American Landscape. New York: Rizzoli.

Bishop, J. C., \& Curtis, M. (2001). Play Today in the Primary School Playground. Buckingham: Open University Press.

Bradley, K. (2015). Open-Source Urbanism: Creating, Multiplying and Managing Urban Commons. Footprint, 16, 91-108.

Brownson, R. C., Eyler, A. A., King, A. C., Brown, D. R., Shyu, Y.-L., \& Sallis, J. F. (2000). Patterns and Correlates of Physical Activity among US Women 40 Years and Older. American Journal of Public Health, 90, 264. https://doi.org/10.2105/AJPH.90.2.264

Bundred, P., Kitchiner, D., \& Buchan, I. (2001). Prevalence of Overweight and Obese Children between 1989 and 1998: Population-Based Series of Cross-Sectional Studies. British Medical Journal, 322, 326-328. https://doi.org/10.1136/bmj.322.7282.326

Carp, F., \& Carp, A. (1984). Complementary/Congruence Model of Well Being in for the Community Elderly. In M. P. Altman, J. F. Lawton, \& Wohlwill (Eds.), Elderly People and the Environment (pp. 279-336). New York: Plenum.

https://doi.org/10.1007/978-1-4899-2171-0_9

Carr, S., Francis, M., Rivlin, L. G., \& Stone, A. M. (1992). Public Space (Cambridge Series in Environment and Behavior). Cambridge: Cambridge University Press.

Chandler, T. (1978). The Man-Modified Climate of Towns. In J. Lenihan, \& W. W. Fletcher (Eds.), The Built Environment, Environment and Man (Volume 8). London: Blackie.

Danzer, G. A. (1987). Public Places: Exploring Their History (the Nearby History Series). Nashville, TN: American Association for State and Local History.

De Vaus, D. (2001). Research Design in Social Research. London: Sage Publication.

Dempsey, N., \& Burton, M. (2012). Defining Place-Keeping: The Long-Term Management of Public Spaces. Urban Forestry \& Urban Greening, 11, 11-20. https://doi.org/10.1016/j.ufug.2011.09.005

Dunnett, N., \& Qasim, M. (2000). Perceived Benefits to Human Well-Being of Urban Gardens. HortTechnology, 10, 40-45. https://doi.org/10.21273/HORTTECH.10.1.40

Ferre, M., Guitart, A., \& Ferret, M. (2006). Children and Playgrounds in Mediterranean Cities. Children's Geographies, 4, 173-183. https://doi.org/10.1080/14733280600806999

Francis, J., Giles-Corti, B., Wood, L., \& Knuiman, M. (2012). Creating Sense of Community: The Role of Public Space. Journal of Environmental Psychology, 32, 401-409. https://doi.org/10.1016/j.jenvp.2012.07.002

Francis, M. (1995). Childhood's Garden: Memory and Meaning of Gardens. Children's Environments, 12, 182-191.

Griffin, S., Wilson, D., Wilcox, S., Buck, J., \& Ainsworth, B. (2008). Physical Activity In- 
fluences in a Disadvantaged African American Community and the Communities' Proposed Solutions. Health Promotion Practice, 9, 180-190. https://doi.org/10.1177/1524839906296011

Gürer, N., Imren Güzel, B., \& Kavak, I. (2017). Evaluation on Living Public Spaces and Their Qualities-Case Study from Ankara Konur, Karanfil and Yüksel Streets. IOP Conference Series: Materials Science and Engineering, 245, Article ID: 072038. https://doi.org/10.1088/1757-899X/245/7/072038

Henderson, K., Neff, L., Shape, P., Greaney, M., Royce, S., \& Ainsworth, B. (2001). "It Takes a Village" to Promote Physical Activity: The Potential for Public Park and Recreation Departments. Journal of Park and Recreation Administration, 19, 23-41.

Kahana, E., Lovegreen, L. et al. (2003). Person, Environment, and Person-Environment Fit as Influences on Residential Satisfaction of Elders. Environment and Behavior, 35, 434-453. https://doi.org/10.1177/0013916503035003007

Kallus, R. (2001). From Abstract to Concrete: Subjective Reading of Urban Space. Journal of Urban Design, 6, 129-150. https://doi.org/10.1080/13574800120057818

Krenichyn, K. (2006). "The Only Place to Go and Be in the City": Women Talk about Exercise, Being Outdoors, and the Meanings of a Large Open Park. Health \& Place, 12, 631-643. https://doi.org/10.1016/j.healthplace.2005.08.015

Lloyd, K., Burden, J., \& Kieva, J. (2008). Young Girls and Urban Parks: Planning for Transition through Adolescence. Journal of Park and Recreation Administration, 26, 21-38.

Mandeli, K. (2019). Public Space and the Challenge of Urban Transformation in Cities of Emerging Economies: Jeddah Case Study. Cities, 95, Article ID: 102409. https://doi.org/10.1016/j.cities.2019.102409

Mandeli, K. N. (2010). Promoting Public Space Governance in Jeddah, Saudi Arabia. Cities, 27, 443-455. https://doi.org/10.1016/j.cities.2010.03.001

Mandeli, K. N. (2011). Public Spaces in a Contemporary Urban Environment: Multi-Dimensional Urban Design Approach for Saudi Cities. PhD, Newcastle upon Tyne: University of Newcastle upon Tyne, School of Architecture, Planning and Landscape, Global Urban Research Unit (GURU).

Maruani, T., \& Amit-Cohen, I. (2007). Open Space Planning Models: A Review of Approaches and Methods. Landscape and Urban Planning, 81, 1-13. https://doi.org/10.1016/j.landurbplan.2007.01.003

McCormack, G. R., Rock, M., Toohey, A. M., \& Hignell, D. (2010). Characteristics of Urban Parks Associated with Park Use and Physical Activity: A Review of Qualitative Research. Health and Place, 16, 712-726. https://doi.org/10.1016/j.healthplace.2010.03.003

Noble, D. G., Bashford, R. I., \& Baillie, S. R. (2000). The Breeding Bird Survey 1999. BTO Research Report 247, Thetford: British Trust for Ornithology.

Ozguner, H., \& Kendle, A. (2006). Public Attitudes towards Naturalistic versus Designed Landscapes in the City of Sheffield (UK). Landscape and Urban Planning, 74, 139-157. https://doi.org/10.1016/j.landurbplan.2004.10.003

Ross, C. E. (2000). Walking, Exercising, and Smoking: Does Neighborhood Matter? Social Science \& Medicine, 51, 265-274. https://doi.org/10.1016/S0277-9536(99)00451-7

Rugg, J. (2000). Defining the Place of Burial: What Makes a Cemetery a Cemetery? Mortality, 5, 259-275. https://doi.org/10.1080/713686011

Runte, A. (1987). National Parks: The American Experience. Lincoln, NE: University of Nebraska Press. 
Saleh, M. A. E. (1998). Place Identity: The Visual Image of Saudi Arabian Cities. Habitat International, 22, 149-164. https://doi.org/10.1016/S0197-3975(97)00033-7

Schenker, H. M. (1995). Parks and Politics during the Second Empire in Paris. Landscape Journal, 14, 201-219. https://doi.org/10.3368/lj.14.2.201

Sirgy, M. J., \& Cornwell, T. (2002). How Neighborhood Features Affect Quality of Life. Social Indicators Research, 59, 79-114. https://doi.org/10.1023/A:1016021108513

Somper, J. P. (2001). Market Research: Property Values and Trees Feasibility Study. Gloucestershire: National Urban Forestry Unit.

Turner, T. (1992). Open Space Planning in London: From Standards per 1000 to Green Strategy. The Town Planning Review, 63, 365-386. https://doi.org/10.3828/tpr.63.4.1703v67051278442

van Hecke, L., Deforche, B., Van Dyck, D., De Bourdeaudhuij, I., Veitch, J., \& Van Cauwenberg, J. (2016). Social and Physical Environmental Factors Influencing Adolescents' Physical Activity in Urban Public Open Spaces: A Qualitative Study Using Walk-Along Interviews. PLoS ONE, 11, e0155686. https://doi.org/10.1371/journal.pone.0155686

Wen, M., Zhang, X., Harris, C. D., Holt, J. B., \& Croft, J. B. (2013). Spatial Disparities in the Distribution of Parks and Green Spaces in the USA. Annals of Behavioral Medicine, 45, S18-S27. https://doi.org/10.1007/s12160-012-9426-x 